\title{
Self-organized $\mathrm{In}_{\mathbf{0 . 4}} \mathrm{Ga}_{0.6}$ As quantum-dot lasers grown on $\mathrm{Si}$ substrates
}

\author{
K. K. Linder, J. Phillips, O. Qasaimeh, X. F. Liu, S. Krishna, and P. Bhattacharya ${ }^{a}$ \\ Department of Electrical Engineering and Computer Science, Solid State Electronics Laboratory, \\ University of Michigan, Ann Arbor, Michigan 48109-2122 \\ J. C. Jiang \\ Department of Materials Science and Engineering, University of Michigan, Ann Arbor, \\ Michigan 48109-2136
}

(Received 12 November 1998; accepted for publication 6 January 1999)

\begin{abstract}
We report growth of self-organized $\mathrm{In}_{0.4} \mathrm{Ga}_{0.6}$ As quantum dots on $\mathrm{Si}$ substrates by molecular-beam epitaxy. Low-temperature $(17 \mathrm{~K})$ photoluminescence spectra show that the optical properties of $\mathrm{In}_{0.4} \mathrm{Ga}_{0.6}$ As quantum dots grown on $\mathrm{Si}$ are comparable to quantum dots grown on GaAs substrates. We also present preliminary characteristics of $\mathrm{In}_{0.4} \mathrm{Ga}_{0.6}$ As quantum-dot lasers grown on $\mathrm{Si}$ substrates. Light versus current measurements at $80 \mathrm{~K}$ under pulsed bias conditions show that $I_{\mathrm{th}}=3.85 \mathrm{kA} / \mathrm{cm}^{2}$. The lasing spectral output has a peak emission wavelength of $1.013 \mu \mathrm{m}$ and a linewidth (full width at half maximum) of $\sim 4 \AA$ at the threshold. (C) 1999 American Institute of Physics. [S0003-6951(99)02010-0]
\end{abstract}

GaAs-based light sources on Si-based circuits would eventually enable chip-to-chip and system-to-system optical interconnections. The $4 \%$ lattice mismatch and the $250 \%$ thermal expansion coefficient difference between GaAs and $\mathrm{Si}$ makes direct growth of high-quality GaAs on Si very difficult, resulting in high dislocation densities $\left(>10^{8} \mathrm{~cm}^{-2}\right)$. GaAs-based quantum-well lasers and lightemitting diodes (LEDs) grown on $\mathrm{Si}$ substrates have been demonstrated in the past but with marginal performance. ${ }^{1,2}$ Several methods have been proposed to improve the luminescence of GaAs-based lasers on $\mathrm{Si}$, including patterned growth and high-temperature anneals. ${ }^{3}$ One promising method for improving the luminescence of GaAs-based lasers on $\mathrm{Si}$ involves growth of highly strained threedimensional islands, or quantum dots, by the StranskiKrastanov growth mode, within the active region. ${ }^{4,5}$ Both edge- and surface-emitting lasers, with defect-free $\mathrm{In}(\mathrm{Ga}, \mathrm{Al}) \mathrm{As} / \mathrm{Ga}(\mathrm{Al}) \mathrm{As}$ self-organized quantum-dot active regions on GaAs substrates have been achieved. ${ }^{6,7}$ These lasers have exhibited low threshold current and high gain comparable to quantum-well lasers. Quantum-dot lasers, therefore, hold great promise for future communication and optical interconnect applications. Growth of InAs self-organized quantum dots on Si have been previously reported. ${ }^{8}$ Recently, Egawa et al. have demonstrated AlGaAs/GaAs laser diodes on Si grown by "droplet" epitaxy with GaAs island-like active regions. ${ }^{9}$ In this letter, we report the growth of selforganized $\mathrm{In}_{0.4} \mathrm{Ga}_{0.6} \mathrm{As}$ quantum dots on $\mathrm{Si}$ substrates by molecular-beam epitaxy and also present preliminary results of $\mathrm{In}_{0.4} \mathrm{Ga}_{0.6} \mathrm{As}$ quantum-dot lasers grown on $\mathrm{Si}$ substrates.

Considerable attention was given to improve the growth conditions of the initial GaAs layer to prevent defects from propagating to the active region. The laser structures, shown in Fig. 1, were grown on (100)-oriented Si substrates, misoriented $2^{\circ}$ toward the [110] direction to reduce the formation of stacking faults at the GaAs/Si interface. ${ }^{10}$ Oxide de-

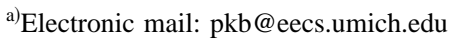

sorption was performed at $830{ }^{\circ} \mathrm{C}$ for $30 \mathrm{~min}$. The substrate was then cooled to $350{ }^{\circ} \mathrm{C}$ and $\mathrm{As}_{4}$ passivated for $5 \mathrm{~min}$ to improve the crystal orientation of the initial GaAs layer. ${ }^{10} \mathrm{~A}$ $300 \AA \mathrm{GaAs}$ layer was then grown at the same temperature. This was followed by the growth of a $1.5 \mu \mathrm{m}$ GaAs layer at $650{ }^{\circ} \mathrm{C}$. The GaAs layer was then annealed using two thermal cycles between 300 and $780^{\circ} \mathrm{C}$, followed by a $10 \mathrm{~min}$ anneal at $780^{\circ} \mathrm{C}$. An additional $1.5 \mu \mathrm{m}$ GaAs layer was grown followed by another thermal cycle anneal, followed by growth of another $1 \mu \mathrm{m} \mathrm{GaAs}$ layer. All the GaAs layers were doped $n$ type with $\mathrm{Si}$. The laser structure was then grown consisting of a 3-5 layer $\mathrm{In}_{0.4} \mathrm{Ga}_{0.6}$ As quantum-dot active region with $15 \AA$ GaAs barriers. The initial dot layer was $8 \mathrm{ML}$ thick; each subsequent layer was 4 ML. The quantum dots were grown at $530^{\circ} \mathrm{C}$ at a rate of $0.1 \mathrm{ML} / \mathrm{sec}$. Cross-sectional transmission electron microscopy (XTEM) of the active region, shown in the inset of Fig. 1, confirms that there is strong strain-induced vertical coupling between dots in successive layers. ${ }^{11}$ Atomic force microscopy (AFM)

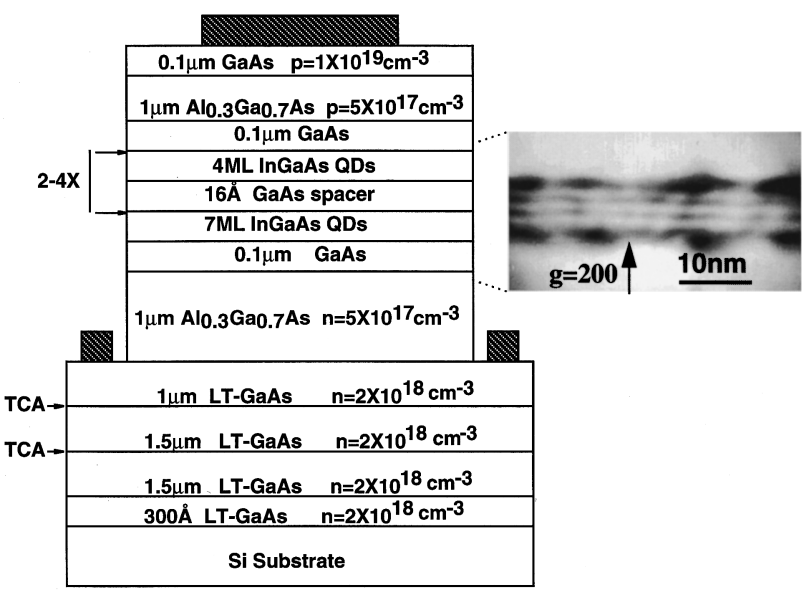

FIG. 1. Schematic of the self-organized $\operatorname{In}_{0.4} \mathrm{Ga}_{0.6}$ As quantum-dot laser heterostructure grown on a $\mathrm{Si}$ substrate. The inset shows the cross-sectional transmission electron microscopy (XTEM) image of the vertically coupled four-dot layer active region. 

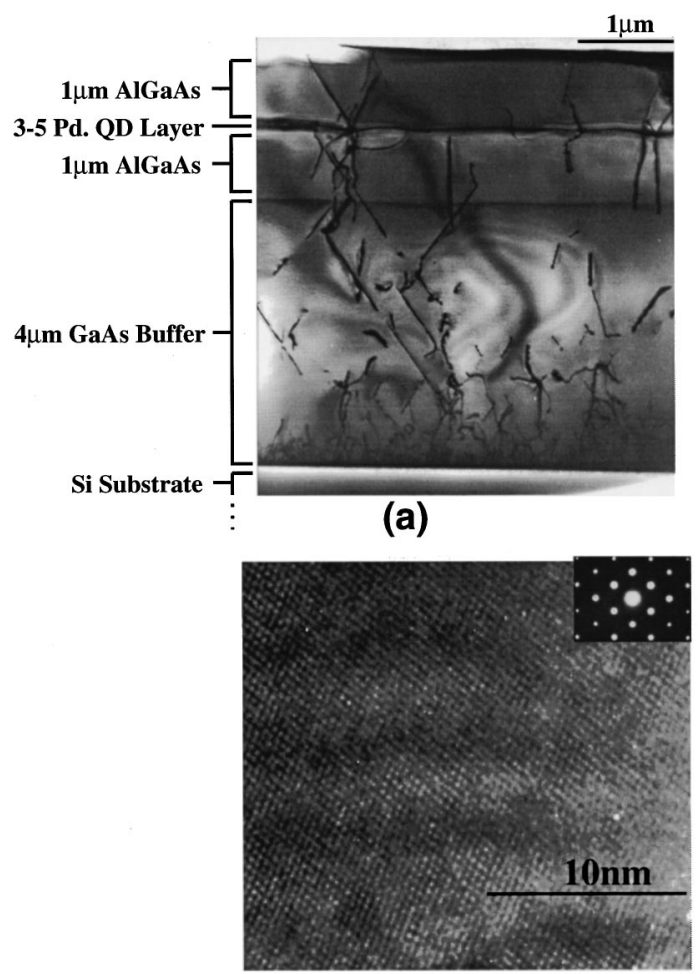

(b)

FIG. 2. (a) Bright-field XTEM of the laser structure and (b) high-resolution XTEM image of three layers of $\mathrm{In}_{0.4} \mathrm{Ga}_{0.6}$ As quantum dots grown on $\mathrm{Si}$.

and plan-view TEM performed on separate samples with a 2 $\mu \mathrm{m} \mathrm{GaAs}$ buffer layer and $8 \mathrm{ML}$ of $\mathrm{In}_{0.4} \mathrm{Ga}_{0.6}$ As growth confirm a dot density $\sim 1.2 \times 10^{11} \mathrm{~cm}^{-2}$.

Bright-field XTEM of the laser structure, shown in Fig. 2(a), shows the formation of threading dislocations at the $\mathrm{GaAs} / \mathrm{Si}$ interface. However, the defect density appears to be significantly smaller at the quantum-dot active region, as expected. High-resolution XTEM imaging of three coupled dots, shown in Fig. 2(b), indicates that the dots themselves may be defect free. To estimate the optical properties of the dots grown on $\mathrm{Si}$, we have compared low-temperature (17 K) photoluminescence (PL) spectra, shown in Fig. 3, of the $\mathrm{In}_{0.4} \mathrm{Ga}_{0.6}$ As quantum-dot laser structure grown on $\mathrm{Si}$ with a similar working laser structure grown on GaAs. We found that the single emission peak intensity of the dots grown on $\mathrm{Si}$, centered at $1.053 \mu \mathrm{m}$, is nearly half of that grown on

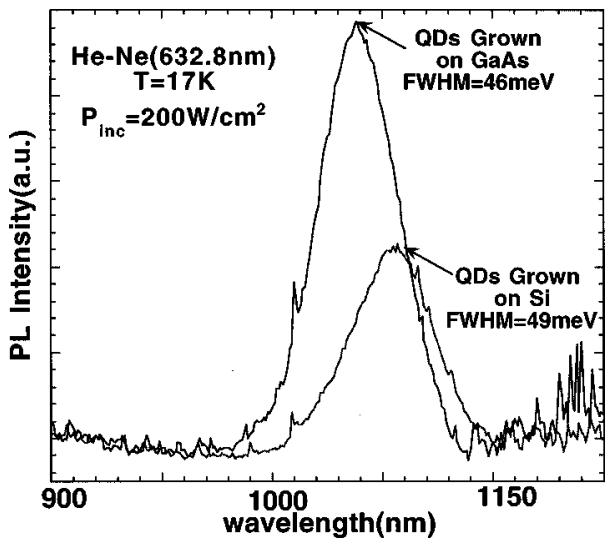

FIG. 3. Low-temperature $(17 \mathrm{~K})$ photoluminescence $(\mathrm{PL})$ spectra of $\mathrm{In}_{0.4} \mathrm{Ga}_{0.6}$ As quantum-dot lasers grown on $\mathrm{Si}$ and $\mathrm{GaAs}$ substrates.

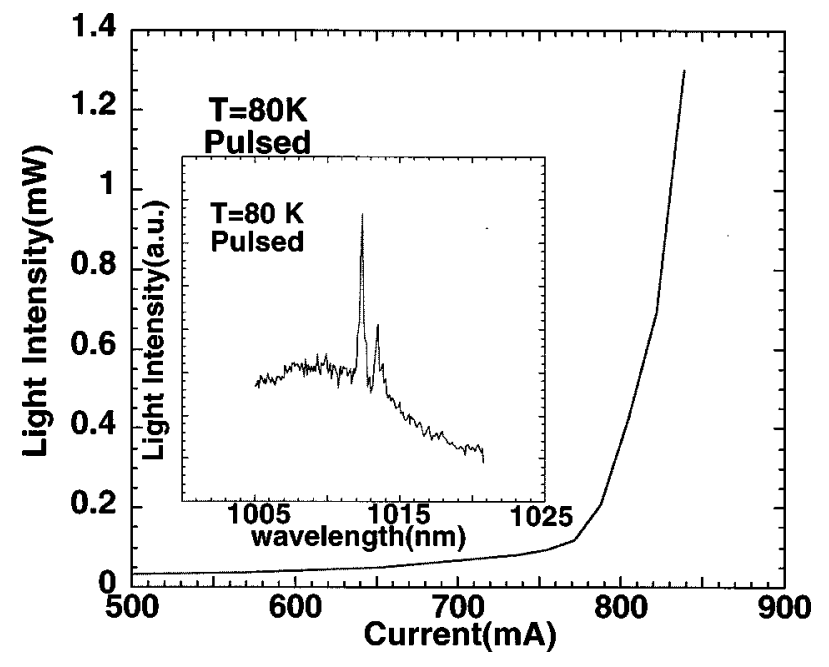

FIG. 4. Preliminary $L-I$ characteristics of the $\operatorname{In}_{0.4} \mathrm{Ga}_{0.6} \mathrm{As}$ quantum-dot laser. The inset shows the lasing emission spectra.

GaAs, centered at $1.038 \mu \mathrm{m}$. Based on previously reported data from quantum dots grown on GaAs substrates, ${ }^{12}$ we believe the peak is related to ground-state $(\mathrm{e} 1-\mathrm{hh} 1)$ bound exciton transitions. The emission peak linewidth [full width at half maximum (FWHM)] of the dots grown on $\mathrm{Si}$ (49 $\mathrm{meV})$ and $\mathrm{GaAs}(46 \mathrm{meV})$ are nearly the same. The large linewidth results from inhomogeneous broadening due to the finite-size distribution of the dots. We suspect that the reduction in PL intensity for the sample grown on Si results from nonradiative recombination losses at defects near the quantum-dot active region. These results are very optimistic and we expect to get better luminescence by optimizing the buffer layer growth conditions.

Broad-area edge-emitting lasers were fabricated using standard photolithography techniques. The $n$ and $p$ contacts used $\mathrm{Ni} / \mathrm{Ge} / \mathrm{Au} / \mathrm{Ti} / \mathrm{Au}$ and $\mathrm{Pd} / \mathrm{Zn} / \mathrm{Pd} / \mathrm{Au}$ metallization, respectively. The substrates were thinned to $\sim 70 \mu \mathrm{m}$ and then cleaved to form the mirrors. The cavity length and width were 800 and $50 \mu \mathrm{m}$, respectively. Figure 4 shows light versus current $(L-I)$ characteristics of broad-area lasers, measured at $80 \mathrm{~K}$, under pulsed bias conditions. The measured threshold current density for this device is 3.85 $\mathrm{kA} / \mathrm{cm}^{2}$. The laser spectra, shown in the inset of Fig. 4, indicate the emission wavelength is $1.013 \mu \mathrm{m}$ with a linewidth (FWHM) $\sim 4 \AA$ at the threshold $\left(I_{\text {th }}=788 \mathrm{~mA}\right)$. We believe that the spectra shift toward smaller wavelengths with increasing current density is due to either the filling of smallersized dots or state-filling effects. Albeit weak in performance, this is a demonstration of lasing from $\mathrm{In}_{0.4} \mathrm{Ga}_{0.6} \mathrm{As}$ self-organized quantum dots grown on $\mathrm{Si}$ substrates.

In conclusion, we have grown self-organized $\mathrm{In}_{0.4} \mathrm{Ga}_{0.6}$ As quantum dots on $\mathrm{Si}$. The optical properties of $\mathrm{In}_{0.4} \mathrm{Ga}_{0.6} \mathrm{As}$ dots grown on $\mathrm{Si}$ are comparable to $\mathrm{In}_{0.4} \mathrm{Ga}_{0.6} \mathrm{As}$ dots grown on GaAs substrates. We have also characterized a $\mathrm{In}_{0.4} \mathrm{Ga}_{0.6}$ As quantum-dot laser grown on Si. At $80 \mathrm{~K}$ and under pulsed bias conditions, the lasers have a threshold current density of $3.85 \mathrm{kA} / \mathrm{cm}^{2}$ with a linewidth (FWHM) $\sim 4 \AA$ at the threshold. 
The authors would also like to thank Dr. D.-H. Zhu for assistance with the molecular-beam epitaxy growth. The work is being supported by the Army Research Office and the National Science Foundation.

${ }^{1}$ J. P. van der Ziel and N. Chand, J. Appl. Phys. 68, 2731 (1990).

${ }^{2}$ H. K. Choi, C. A. Wang, and N. H. Karam, Appl. Phys. Lett. 59, 2634 (1991).

${ }^{3}$ T. Egawa, Y. Hasegawa, T. Jimbo, and M. Umeno, Jpn. J. Appl. Phys., Part 1 31, 791 (1992).

${ }^{4}$ L. Goldstein, F. Glas, J. Y. Marzin, M. N. Charasse, and G. Leroux, Appl. Phys. Lett. 47, 1099 (1985).

${ }^{5}$ P. R. Berger, K. Chang, P. Bhattacharya, J. Singh, and K. K. Bajaj, Appl. Phys. Lett. 53, 684 (1988).
${ }^{6}$ K. Kamath, P. Bhattacharya, T. Soznowski, T. Norris, and J. Phillips, Electron. Lett. 32, 1374 (1996).

${ }^{7}$ D. Bimberg, N. N. Ledenstov, O. Steir, V. M. Ustinov, P. S. Kop'ev, and Z. I. Alferov, Jpn. J. Appl. Phys., Part 1 35, 1311 (1996).

${ }^{8}$ J. M. Gérard, O. Cabrol, and B. Sermage, Appl. Phys. Lett. 68, 3123 (1996).

${ }^{9}$ T. Egawa, A. Ogawa, T. Jimbo, and M. Umeno, Proceedings of the 1996 IEEE International Electron Devices Meeting (IEEE, San Francisco, CA, 1996), p. 1208.

${ }^{10}$ A. Georgakilas, P. Panayotatos, J. Stoemenos, J.-L. Mourrain, and A. Christou, J. Appl. Phys. 71, 2679 (1992).

${ }^{11}$ J. Tersoff, C. Teichert, and T. G. Legally, Phys. Rev. Lett. 76, 1675 (1996).

${ }^{12}$ M. Grundmann, N. N. Ledenstov, O. Steir, D. Bimberg, V. M. Ustinov, P. S. Kop'ev, and Z. I. Alferov, Appl. Phys. Lett. 68, 979 (1996). 